\title{
Peripheral retinal ablation in the treatment of proliferative diabetic retinopathy: a three-year interim report of a randomised, controlled study using the argon laser
}

\author{
B. L. HERCUlES, I. I. GAYED, S. B. LUCAS, AND JULIE JEACOCK \\ From the University Department of Ophthalmology and Computational Group, Faculty of Medicine and \\ Royal Eye Hospital, Manchester
}

SUMMARY A randomised controlled trial is reported of 94 patients with a symmetrical proliferative diabetic retinopathy involving the optic disc, who were treated by a peripheral retinal ablation technique using the argon laser. A highly significant difference in mean cumulative deterioration of visual acuity and blindness was shown in all but the late stages of the disease process between treated and untreated eyes. The untreated eyes exhibited far worse results. The earlier photocoagulation is initiated in the course of the proliferative process in this disease to control or preferably eliminate optic disc neovascularisation, the better the visual prognosis.

In England and Wales diabetic retinopathy is responsible for $7 \%$ of all new blind registrations and up to $20 \%$ in the middle-aged (Sorsby, 1972). Patients with the proliferative form of the disorder have been estimated by Deckert et al. (1967) and Caird et al. (1968) to progress to blindness in 50\% of cases after five years. Taylor and Dobree (1970) noted that their patients with proliferative retinopathy had an incidence of optic disc neovascularisation of 68 to $73.25 \%$.

Visual prognosis is far worse if the proliferative retinopathy involves the optic disc region (Deckert et al., 1967); $50 \%$ of patients in this category are blind within two to three years. Neovascularisation of the optic disc frequently leads to vitreous haemorrhage and blindness (Patz and Berkow, 1968). In their three-year study Beetham et al. (1970) showed that $85 \%$ (29 patients) of untreated eyes with vitreous haemorrhage bled from new vessels at the optic disc. Caird et al. (1968) showed that after a vitreous haemorrhage one-third of involved eyes were blind within one year and one-third had vision which was permanently impaired. Patz and Berkow (1968) found that the second (good) eye in patients blind in the other eye frequently became blind through extension of the proliferative process in a short period of time $(50 \%$ within one year). Meyer-

Address for reprints: B. L. Hercules, FRCS, 15 Chestnut Drive, Sale, Cheshire
Schwickerath (1954) showed that retinal changes in diabetes mellitus may be arrested or reversed by light coagulation. He further showed that regression could occur in newly formed vessels at retinal level even though treatment was remote from the lesion. Okun (1968); Krill et al. (1971a, b); and Taylor and Dobree (1970) noted regression of disc neovascularisation occasionally when extensive xenon-arc photocoagulation of the diabetic retina had been undertaken.

A circumferential ablation technique using the ruby laser was described first by Aiello et al. (1969). In a subsequent series (Beetham et al., 1970) 30\% of patients with optic disc neovascularisation showed significant reduction of new vessels after treatment. James and L'Esperance (1974) treated 52 eyes with proliferation at the optic disc by a retinal ablation technique with the argon laser. After treatment $42 \%$ of eyes showed obliteration of disc neovascularisation, and $33 \%$ showed a significant response.

Interim reports from a multicentre study in the United States using both xenon arc and argon laser (Diabetic Retinopathy Study Research Group, 1976) and England (British Multicentre Photocoagulation Trial, 1977) using only xenon arc photocoagulation indicate that photocoagulation confers real benefits on the treated eye. This difference between treated and untreated eyes was enhanced by previous vitreous haemorrhage, as, untreated, this has a poor 
prognosis. In a retrospective study Little et al. (1976) compared photocoagulation techniques in the treatment of proliferative diabetic retinopathy. 'Focal' treatment was found to be dangerous, 'feeder-frond' treatment was effective for only a short period, and 'pan-retinal' treatment was both safe and effective. In combination the last two techniques showed a marginal summation of effect.

In view of the suggestions of other workers, and before any of their results were available, a trial was initiated in Manchester in 1973 to attempt elimination of optic-disc neovascularisation in the diabetic patient by peripheral retinal ablation and to evaluate the effects of argon laser photocoagulation on the course of the disease.

\section{Patients and methods}

Those patients found on routine screening to have diabetic retinopathy were referred from general practitioners, diabetic clinics, and ophthalmic units in the north-west of England; 94 consecutive patients (56 men and 38 women) who conformed to the study protocol were admitted to the trial. The criteria for inclusion were (1) that both eyes of each patient were similarly affected by a proliferative diabetic process involving the optic disc; observable features of the retinopathy had to be within the same grade when each eye was classified (Table 1); (2) that visual acuity at initial assessment did not differ by more than two lines on the Snellen chart and was at least $6 / 24$ in the worst eye.

Exclusion from the study was made if: (1) The patient's age was greater than 70 years; (2) life expectancy was possibly too short for subsequent assessments; (3) previous pituitary ablation had been undertaken; (4) either eye had received previous xenon arc photocoagulation; (5) intercurrent ocular disease was present; (6) visual acuity was adversely affected by opacities of the media and visual pathways, making retinal photography and

Table 1 Randomisation: population studies of patients in the trial

\begin{tabular}{|c|c|c|c|c|c|c|}
\hline Group & 1 & $1 a$ & $7 q$ & 2 & 3 & Total \\
\hline Age (years): range & $18-64$ & $18-62$ & $25-64$ & $23-65$ & $33-49$ & $18-65$ \\
\hline average & $42 \cdot 4$ & 45 & $40 \cdot 2$ & $39 \cdot 4$ & $41 \cdot 8$ & 41 \\
\hline Diabetes: duration & $2-40$ & 4-36 & $2-40$ & $5-31$ & $10-32$ & $2-40$ \\
\hline $\begin{array}{l}\text { mean and average } \\
\text { duration }\end{array}$ & $16 \cdot 4$ & $17 \cdot 1$ & $15 \cdot 8$ & $18 \cdot 4$ & $16 \cdot 6$ & - \\
\hline insulin-dependent & 33 & 19 & 15 & 37 & 9 & 80 \\
\hline oral hypoglycaemics & 9 & 6 & 3 & 4 & 1 & 14 \\
\hline
\end{tabular}

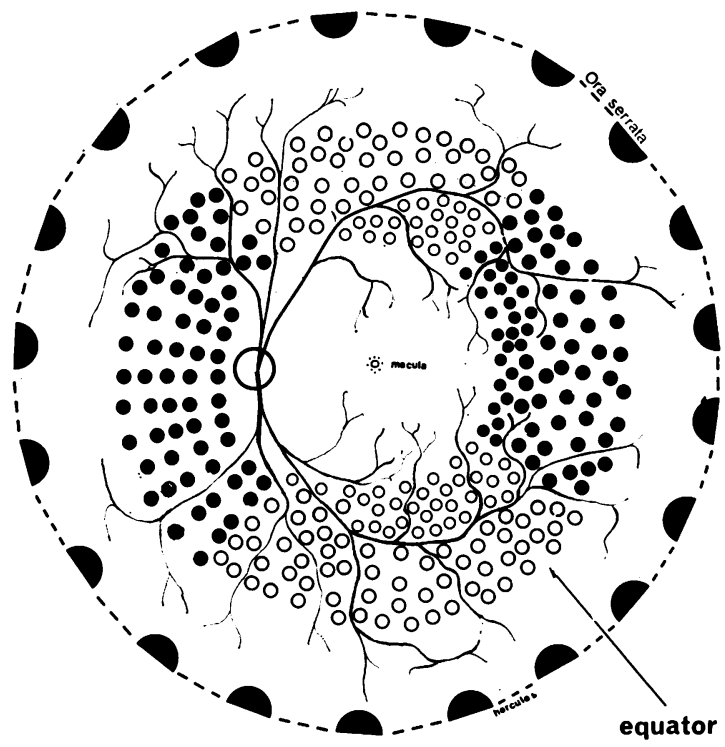

Fig. 1 Technique of peripheral retinal ablation Key symbols:

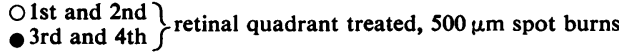

Within macular arcades of vessels, $200 \mu \mathrm{m}$ spot burns

treatment unsatisfactory; and (7) proliferation in the retina had reached the late cicatricial stage with localised traction detachment. Eight patients subsequently receiving treatment to the 'control' eye were removed from the study at that point.

\section{TECHNIQUE}

All treated eyes were subjected to extensive peripheral retinal photocoagulation by means of a Coherent 800 gas-argon laser, incorporating a 3-mirror Goldmann lens in the delivery system (L'Esperance, 1968) when necessary. The procedure was well tolerated after instillation of local anaesthetic drops in all except 2 patients, who required retrobulbar anaesthesia.

Photocoagulation burns were applied within the vascular arcades above and below the macula, but an approximately circular area of radius $2 \frac{1}{2}$ disc diameters, with the fovea at its centre and including the papulomacular bundle, was left untouched. In the nasal fundus photocoagulation was extended centrally to the edge of the optic disc and involved any new vessels arising from this margin. In all meridians photocoagulation was extended anteriorly to the equator using the 3-mirror lens (Fig. 1).

Individual burns with sufficient energy to accomplish minimal retinal blanching were applied so that the observer achieved a uniform response over the 
whole area being treated. Marker burns of $200 \mu \mathrm{m}$ diameter were applied to delineate the central area which was to be avoided. Inside the vascular arcades the $200-\mu \mathrm{m}$ spot diameter was used to create a burn pattern with one burn diameter between applications. Outside the arcades and nasally, the $500-\mu \mathrm{m}$ spot diameter was used exclusively as far as the periphery. In the nasal sector burns were applied from the nasal edge of the optic disc to the equator in radial rows which followed the direction of the nerve fibres.

Energy levels between 0.2 and 0.6 watt were used, though most burns required 0.35 to 0.45 watt. Inferiorly higher energy levels were required than in any other area of the retina. Lower energies of 0.2 watt were almost invariably adequate within the macular vascular arcades of vessels, where the $200 . \mu \mathrm{m}$ spot was used. In other areas utilising the $500-\mu \mathrm{m}$ spot levels up to 0.5 watt were usually required. To complete treatment over 2000 burns were applied to most patients (range 800 to 3000 ). The procedure usually required up to 6 sittings over a week (Fig. 2).

Retreatment of areas which appeared unduly lightly treated and of any patches of untreated retina within the 'target' area of the ablation procedure was undertaken in a number of patients in whom optic disc neovascularisation persisted, and in a small number in whom new vessels recurred. Finally, direct laser photocoagulation of middle- to largesized retinal vessels was avoided, as 3 previous patients had had haemorrhages from such vessels at the time of treatment.

\section{DATA RECORDED}

Patients entering the trial received a full ophthalmic assessment including refraction, tonometry, visual fields, fundus photography, and fluorescein angiography. Patients were not excluded from the study group on the basis of nephropathy or other serious extraocular diabetic problems. However, during and after treatment every attempt was made to achieve good diabetic control by careful medical assessment. The eye to be treated was chosen at random and the untreated eye recorded as a control.

Evaluation of treatment was based on four main criteria: (1) Visual acuity: best corrected visual acuities were obtained at each visit, on subjective testing, by a refractionist who was not aware of the previous visual acuity nor the treated eye. (2) Appearance of the optic discs 6 months after treatment and yearly from that point. Assessment was aided by colour photographs and fluorescein angiograms. (3) Vitreous haemorrhage and other complications including uveitis, glaucoma, and retinal detachment. (4) Blindness: eyes were

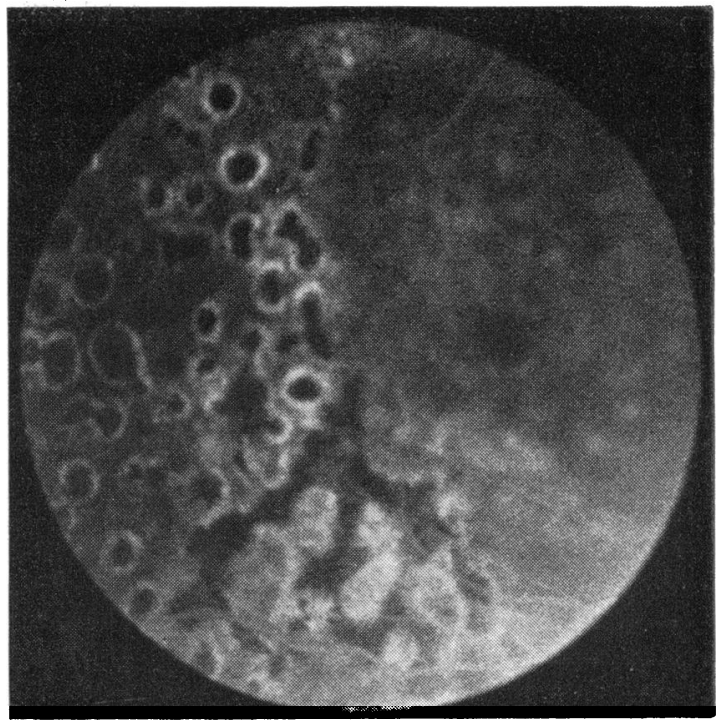

Fig. 2 Fluorescein angiogram: laser scar pattern after peripheral retinal ablation

accepted as blind as an end result of the proliferative process and/or vitreous haemorrhage if this involved a fall of visual acuity to less than $6 / 60$ on the Snellen chart. This result had to be recorded on at least two consecutive visits.

Patients were reviewed at intervals of 2 weeks, 1 month, and 4 to 6 months after the completion of peripheral retinal ablation. Further assessment included visual fields, retinal colour photography, and fluorescein angiography.

CLASSIFICATION FOR DISC NEOVASCULARISATION Patients were divided for the purpose of analysis of results into 3 groups. Selection depended on the ophthalmoscopic and photographic appearances of the neovascularisation at the optic disc at initial assessment. Comparisons were made at follow-up visits, but each patient retained his initial group position throughout the trial.

Group 1.-Disc neovascularisation with no gliosis (supporting connective tissue condensation). This corresponds to the anatomical description of early epi- and peripapillary neovascularisation (Fig. 3) (L'Esperance, 1973). This stage often shows little or no change for years, and occasionally spontaneous regression occurs (Larsen, 1960). This observation enabled a subdivision of the group, dependent on the behaviour of the control eye, after treatment.

Group 1 (a).- 'Active', when the proliferative process at the optic disc in the control eye shows evidence of progression.

Group 1 (q).- 'Quiescent', when there was either 
no change in the neovascularisation at the optic disc or spontaneous regression in the control eye.

Group 2.-Disc neovascularisation with gliosis and/or intravitreal proliferation (Figs. 4 and 5). This conforms to the later stages of epi- and peripapillary neovascularisation described by L'Esperance. Epipapillary changes can convert after marked glial proliferation to more widespread

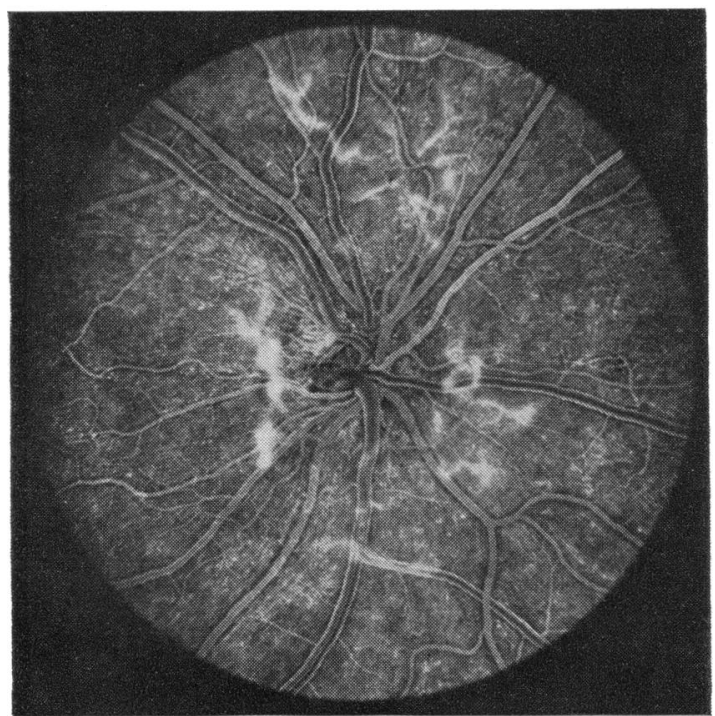

Fig. 3 Fluorescein angiogram: Grade I optic disc neovascularisation

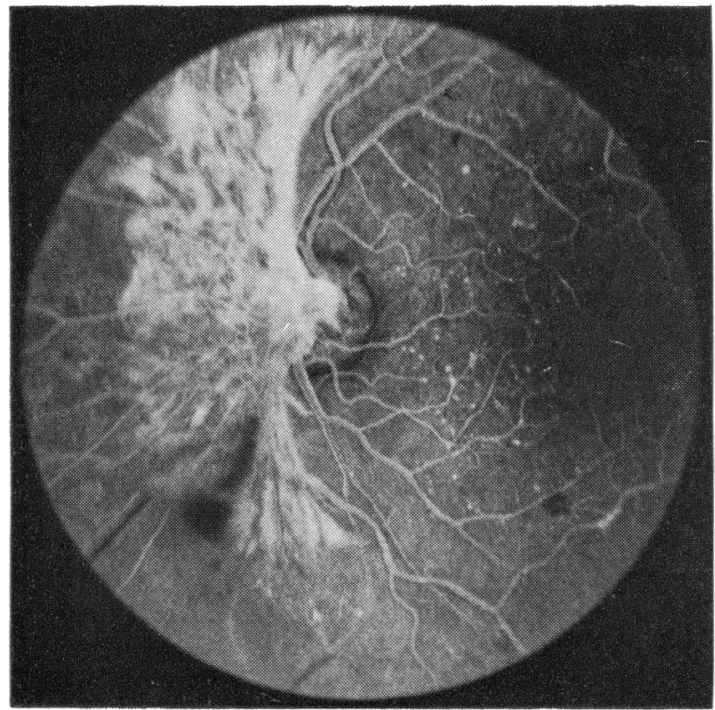

Fig. 5 Fluorescein angiogram: grade II with transtemporal falciform fold of glial tissue (arcuate type of papillo-vitreal neovascularisation) papillovitreal neovascularisation. The peripapillary type can extend 3 to 4 disc diameters across the retinal surface, and, again, can convert to the papillovitreal type. Fig. 5 shows the late phase of group 2 where the arcuate type of papillovitreal neovascularisation is developing.

Group 3.-Untreated grade 2 gradually passes into this stage of massive combined disc neovascu-

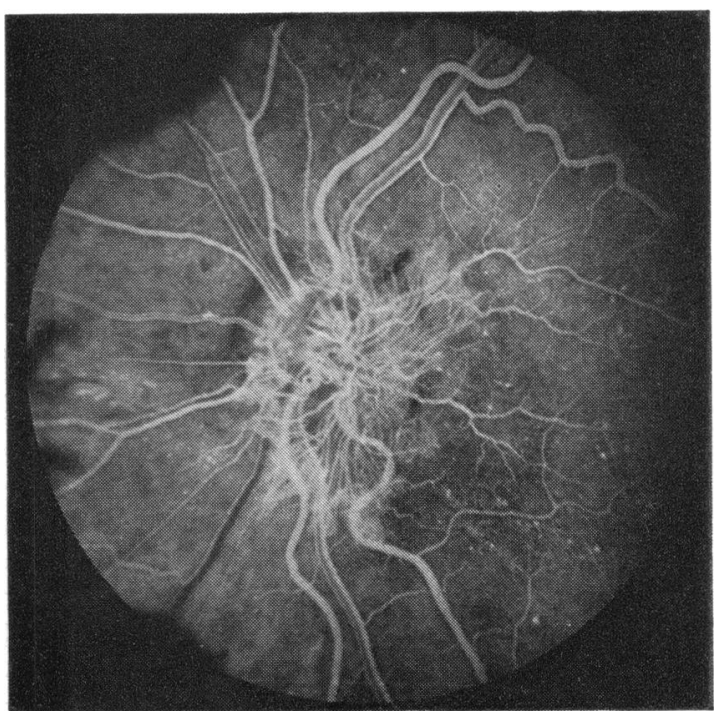

Fig. 4 Fluorescein angiogram: Grade II optic disc neovascularisation. Early stage with onset of connectivetissue condensation in peri- and epipapillary new vessels

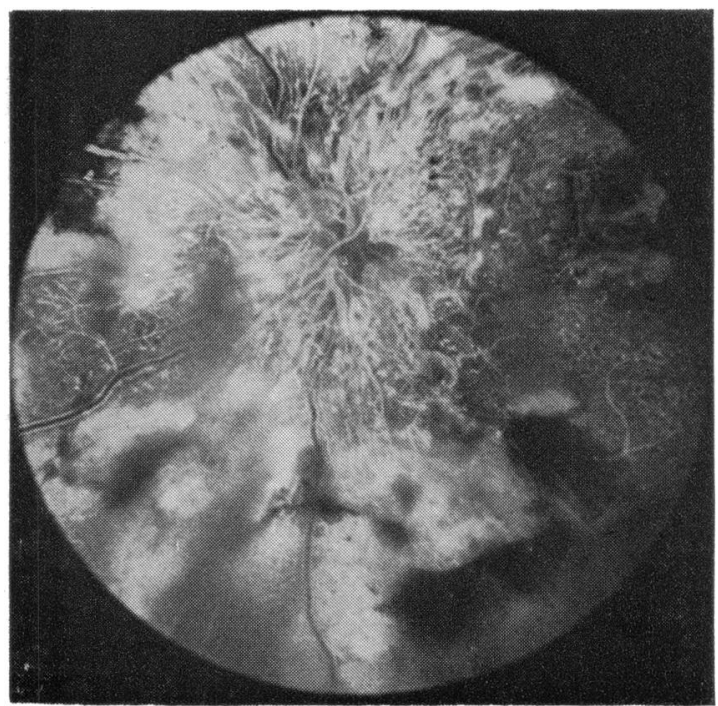

Fig. 6 Fluorescein angiogram: grade III optic; disc neovascularisation with localised traction detachment 
larisation and condensed sheets or bands of connective tissue with significant vitreoretinal traction and/or localised retinal detachment (Fig. 6).

\section{Results}

No adverse effect of extrinsic factors (nephropathy, hypertension, etc.) on the results of photocoagulation

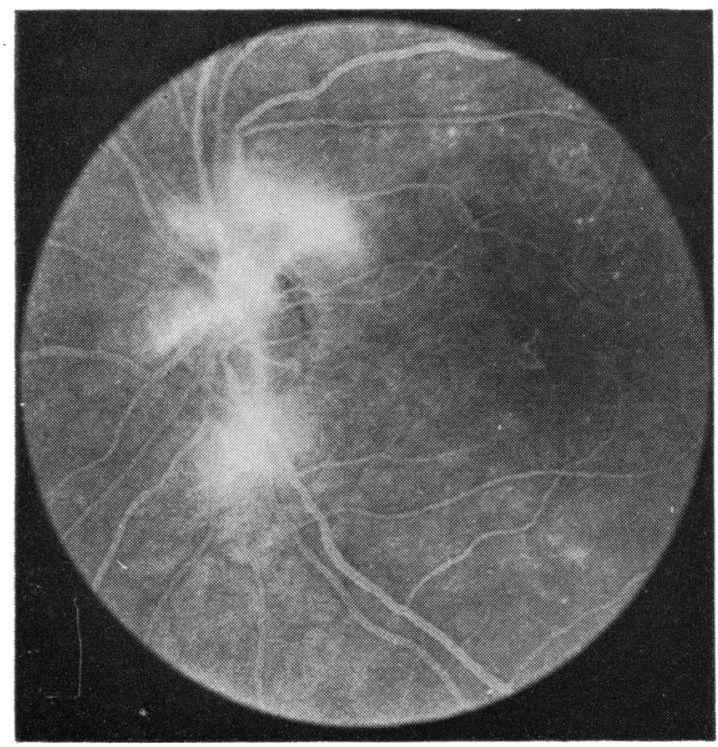

Fig. 7 Fluorescein angiogram: grade I disc neovascularisation before treatment

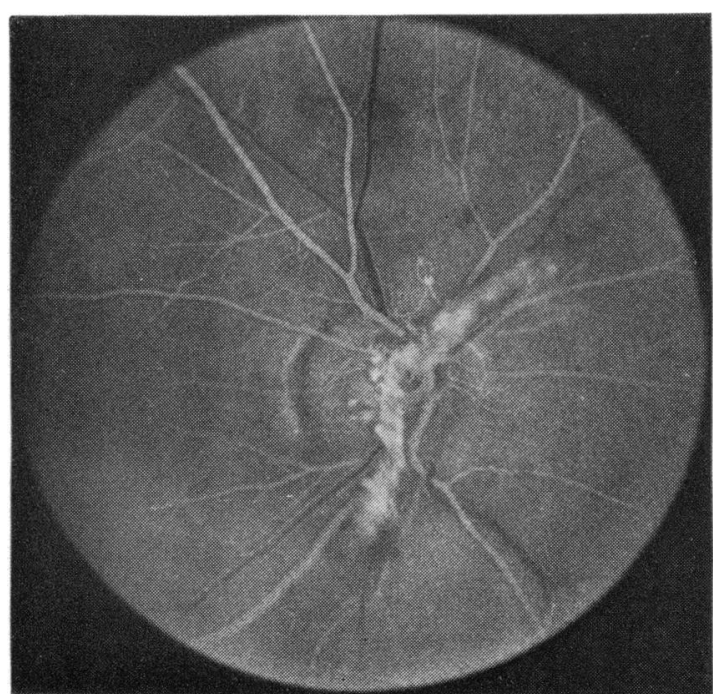

Fig. 9 Fluorescein angiogram: grade II disc neovascularisation before treatment influenced the study, because after randomisation of the eye to be treated we examined 'paired' eyes (see Table 2).

OPTIC DISC NEOVASCULARISATION

Regression of new vessels at the optic disc was achieved in a large number of patients. Each group responded differently to treatment $\left(\chi^{2}=52\right.$, D.F. $=4$,

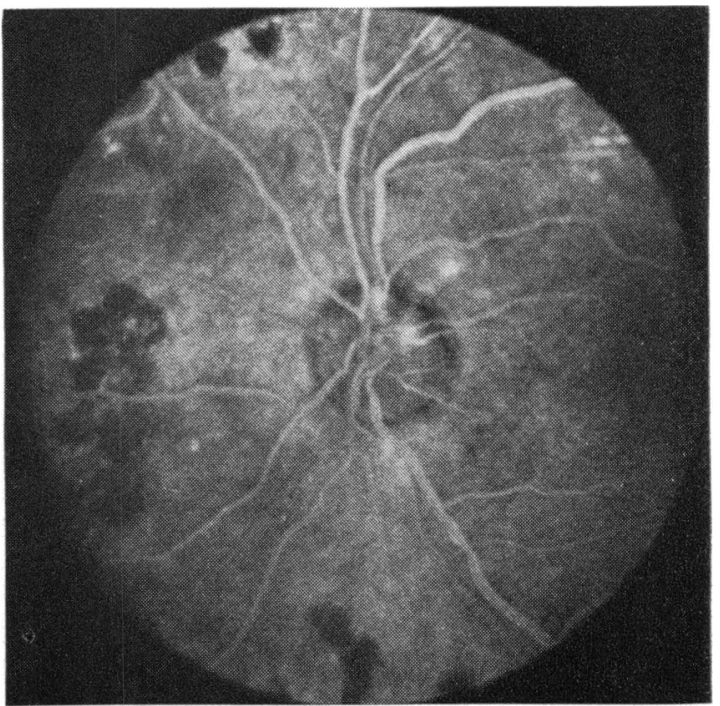

Fig. 8 Fluorescein angiogram: previous optic disc 1 year after treatment, showing almost $100 \%$ regression of new vessels

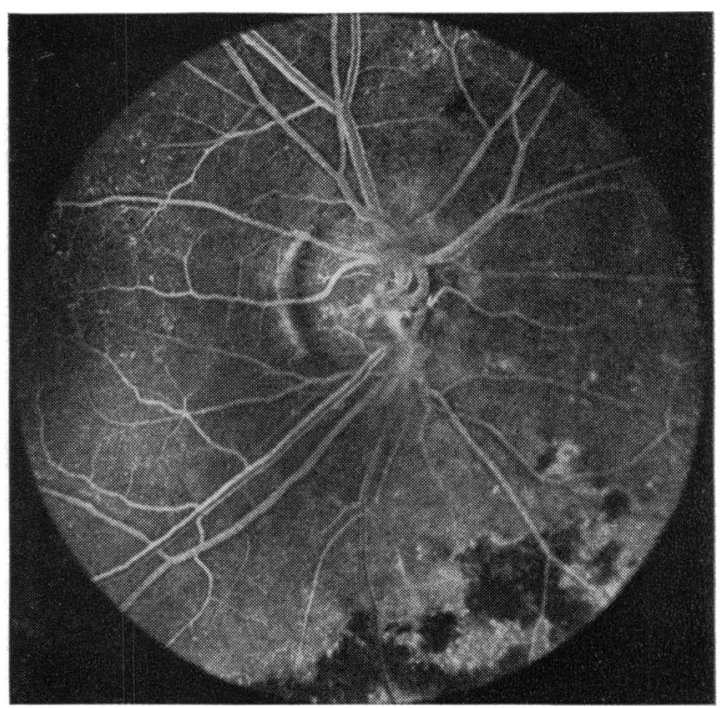

Fig. 10 Fluorescein angiogram: previous optic disc 6 months after treatment, showing small glial scar and regression of new vessels 
$\mathbf{P}<0.001$ ). Table 2 shows that in $36 \%$ of all treated eyes new vessels disappeared completely or almost completely. Improvement was greatest in group 1 patients, where they disappeared in $26 / 43(60 \%)$ of eyes. A significant improvement $(95>R>50)$ occurred in a further $40 \%$ of eyes-all in groups 1 and 2 . Only 2 out of 43 eyes in group $1(4.7 \%)$ showed no significant response, while all 10 in group

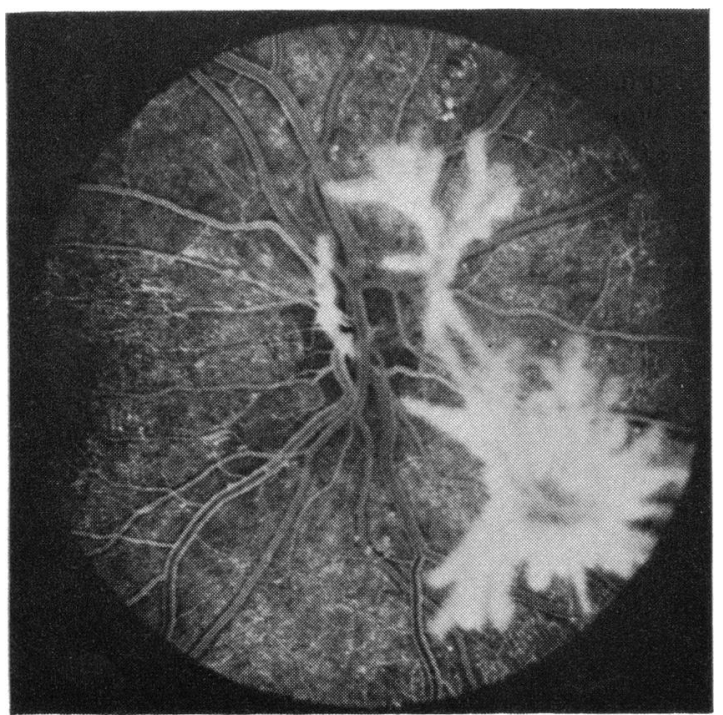

Fig. 11 Fluorescein angiogram: grade II disc neovascularisation before treatment

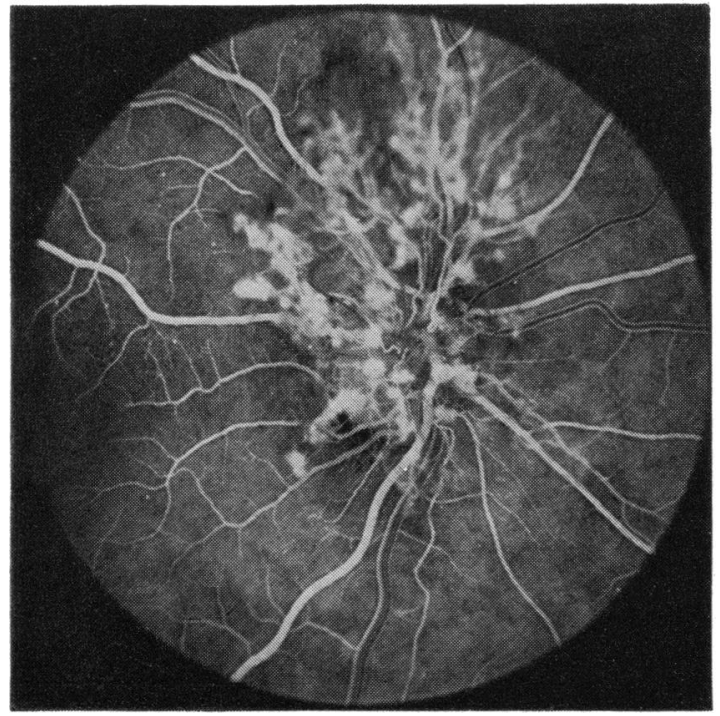

Fig. 13 Fluorescein angiogram: grade II disc neovascularisation before treatment
3 showed this lack of marked improvement (see Figs 7, 8, 9, 10, 11, 12, 13, 14).

VISUAL ACUITY

In group 1 no difference could be shown by the Wilcoxon test in the mean cumulative deterioration in visual acuity between treated and control eyes. In group 2 the difference ranged from very highly

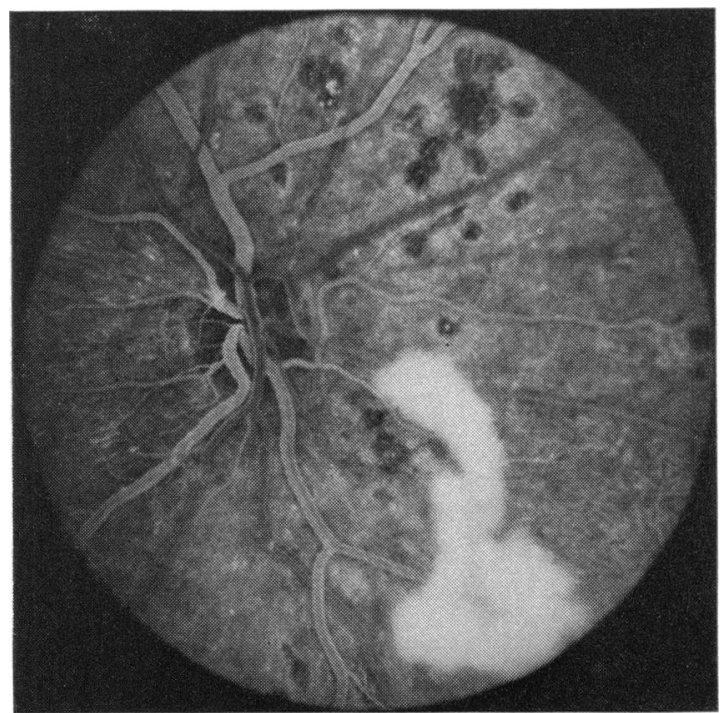

Fig. 12 Fluorescein angiogram: previous optic disc 6 months after treatment, showing $75 \%$ regression of new vessels

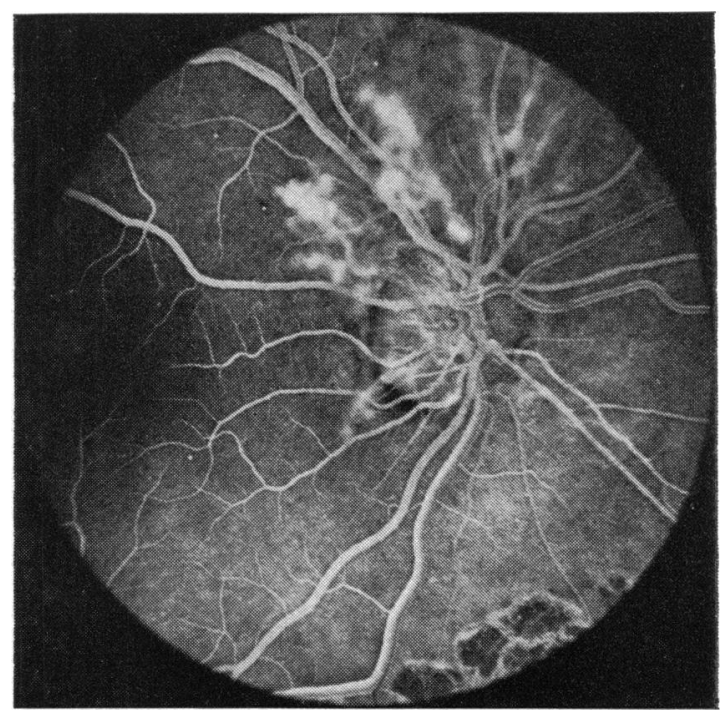

Fig. 14 Fluorescein angiogram: previous disc 7 months after treatment, showing $50 \%$ regression of new vessels 
significant in the first year to significant in the second and third years. In group 3 there was no significant difference in mean cumulative deterioration between the treated and control eyes (Fig. 15 and Table 3).

Group 1 was divided on clinical grounds into 'active' (1a) and 'quiescent' (1q) subgroups. Wilcoxon tests were then applied to the treated and

Table 2 Comparison of the response of optic neovascularisation to treatment

\begin{tabular}{lcccc}
\hline \multicolumn{4}{c}{ Regression of optic disc new vessels } \\
\cline { 2 - 4 } Group & $R>9 j$ & $9 j>R>50$ & $R<50$ & $n$ \\
\hline 1 & 26 & 15 & 2 & 43 \\
2 & 7 & 22 & 10 & 39 \\
3 & 0 & 0 & 10 & 10 \\
Total & & & & 92 \\
\hline
\end{tabular}

$\mathrm{R}=\%$ regression

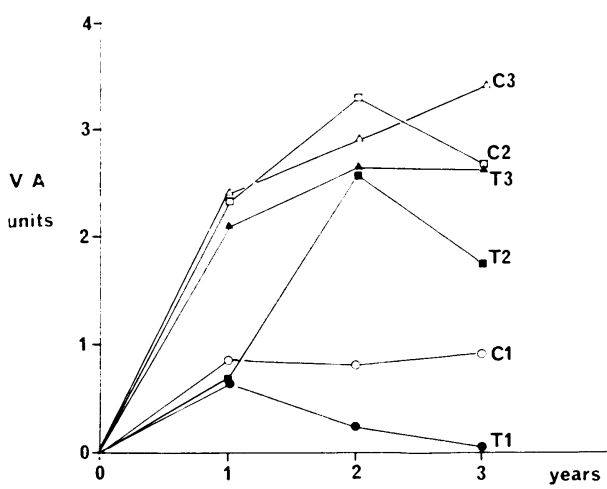

Fig. 15 Mean cumulative deterioration in visual acuity for control and treated eyes in all groups

Table 3 Mean cumulative deterioration of visual acuity ( $V A$ units)

\begin{tabular}{lllllc}
\hline & Year & Treated & Control & $n$ & $P^{*}$ \\
\hline & 1 & 0.62 & 0.85 & 39 & $>0.1$ \\
Group 1 & 2 & 0.24 & 0.83 & 29 & $>0.1$ \\
& 3 & 0.08 & 0.92 & 13 & $>0.1$ \\
& 1 & 0.63 & 2.34 & 41 & $<0.0009$ \\
Group 2 & 2 & 2.56 & 3.30 & 25 & $<0.005$ \\
& 3 & 1.76 & 2.60 & 10 & $<0.025$ \\
& 1 & 2.10 & 2.40 & 10 & $>0.1$ \\
Group 3 & 2 & 2.60 & 2.90 & 6 & $>0.1$ \\
& 3 & 2.50 & 3.40 & 4 & + \\
\hline
\end{tabular}

*Wilcoxon signed ranks matched pair test (one-tail probabilities) +Insufficient data control eyes in both subgroups for each year. In both cases no significant difference could be demonstrated $(P>0 \cdot 10)$. Examination of the resultant graphs suggested that there was no marked divergence between the treated and control means of the quiescent group with time and that this inability to demonstrate significance by the Wilcoxon test in the active group was due to the small sample sizes. Therefore the quiescent group (1q) was pooled, and a Mann-Whitney U-test applied. This showed a significant difference between the active $(1 a)$ untreated subgroup and the pooled quiescent group. There was, however, no significant difference between the active ( $1 a)$ treated group and the pooled quiescent group (Fig. 16 and Table 4).

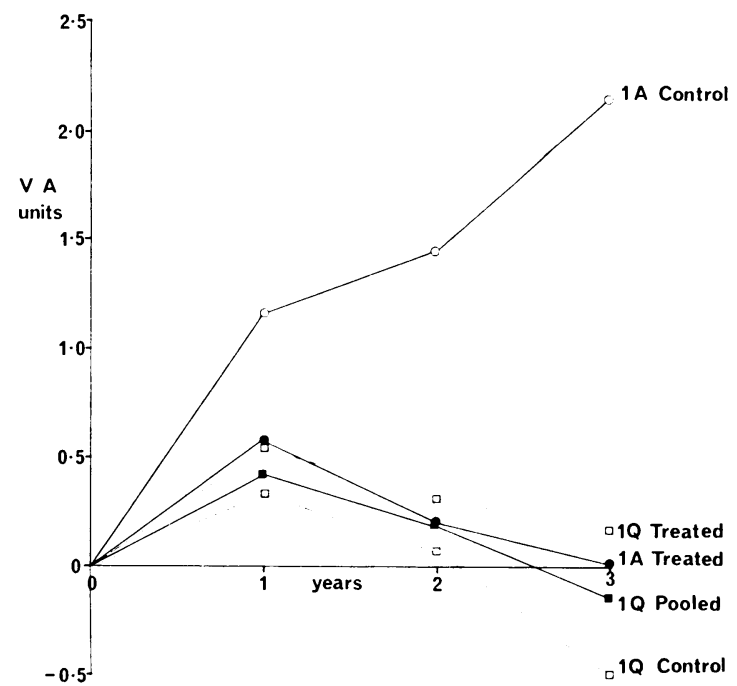

Fig. 16 Mean cumulative deterioration in visual acuity for group 1 active and quiescent subgroups

Table 4 Mean cumulative deterioration of visual acuity for group 1 active and quiescent subgroups

\begin{tabular}{llllll}
\hline \multicolumn{5}{l}{ Active treated/quiescent pooled } \\
\cline { 1 - 3 } Year & Active $T$ & $n$ & Quiescent $P$ & $n$ & $P^{*}$ \\
\hline 1 & 0.58 & 24 & 0.43 & 30 & $>0.48$ \\
2 & 0.19 & 16 & 0.19 & 26 & $>0.31$ \\
3 & 0.0 & 7 & -0.17 & 12 & $>0.10$
\end{tabular}

\begin{tabular}{llcccc}
\hline \multicolumn{5}{l}{ Active control/quiescent pooled } \\
\hline Year & Active $C$ & $n$ & Quiescent $P$ & $n$ & $P^{*}$ \\
\hline 1 & 1.17 & 24 & 0.43 & 30 & $>0.3$ \\
2 & 1.44 & 16 & 0.19 & 26 & $<0.06$ \\
3 & 2.14 & 7 & -0.17 & 12 & $<0.025$ \\
\hline
\end{tabular}

*Mann-Whitney U-test (one-tail probabilities) 
VITREOUS HAEMORRHAGE

The mean time to the onset of vitreous haemorrhage from the start of treatment was evaluated in treated and control eyes. The difference in mean time to vitreous haemorrhage, expressed in years, for all treated groups and for the control groups was very highly significant (Mann-Whitney U-test, $P<0.0001$ ) (Table 5). When the mean time to vitreous haemorrhage between each of the treated groups was compared (Table 6), there was no significant difference between them (Kruskal-Wallis one-way analysis of variance, $P>\mathbf{0} \cdot 1)$. When the control groups were compared there was also no significant difference between the groups (Kruskal-Wallis, $P>0.95)$. It was shown that there were fewer vitreous haemorrhages $\left(\chi^{2}=3 \cdot 52\right.$, D.F. $\left.=1, P=0 \cdot 06\right)$, and that there was a longer time to the onset of such events in treated eyes than in control eyes.

\section{BLINDNESS}

The difference in proportions between treated and control eyes proceeding to blindness within 3 years was significant in groups 1 and 2 . No significant difference was demonstrated in group 3 (McNemar's modified $\chi^{2}$-test) (Table 7).

\section{COMPLICATIONS}

Early complications immediately following treatment were unusual. Some patients had transient myopia which resolved in a few days, and occasional patients suffered an equally transient mild uveitis. Peripheral field loss was initially as much as 15 degrees, reducing to 8 or 10 degrees within a month of treatment. Two patients suffered thrombotic glaucoma and 1 patient a retinal detachment, which was repaired.

\section{Discussion}

Our findings support the views expressed by Beetham et al. (1970); James and L'Esperance (1974); and the Diabetic Retinopathy Study Group (1976) that a retinal ablation technique is effective in reversing the process of neovascularisation at the optic disc, and that photocoagulation is of greatest value in eyes at the earlier stages of the proliferative retinopathy. The earlier a patient was treated in the course of the proliferative retinopathy, the more likelihood of clinically significant regression of optic disc neovascularisation. As new vessels at the optic disc have been shown to have such a poor prognosis, total or significant regression would appear to confer some beneficial effects on the treated eye.

The findings of Caird et al. (1968) on the visual prognosis after a single vitreous haemorrhage illustrate the seriousness of this complication for
Table 5 Comparison of mean times to vitreous haemorrhage from start of treatment in treated and control eyes

\begin{tabular}{lllll}
\hline Treated & $n$ & Control & $n$ & $P^{*}$ \\
\hline 1.42 & 24 & 0.74 & 40 & $<0.0001$ \\
\hline
\end{tabular}

*Mann-Whitney U-test (one-tail probabilities)

Table 6 Comparison of mean times to vitreous haemorrhage between groups for control and treated eyes

\begin{tabular}{llrlclll}
\hline & Group 1 & $n$ & Group 2 & $n$ & Group 3 & $n$ & $P^{*}$ \\
\hline Treated & 1.44 & 9 & 1.79 & 7 & 1.06 & 8 & $>0.10$ \\
Control & 0.70 & 15 & 0.79 & 19 & 0.67 & 6 & $>0.95$
\end{tabular}

*Kruskal-Wallis (one-tail probabilities)

Table 7 Summary of patients proceeding to blindness within 3 years

\begin{tabular}{lccc}
\hline Outcome & Group 1 & Group 2 & Group 3 \\
\hline Both blind & 1 & 2 & 3 \\
$\begin{array}{l}\text { Treated blind }+ \\
\text { control sighted }\end{array}$ & 0 & 1 & 0 \\
$\begin{array}{l}\text { Control blind }+ \\
\text { treated sighted }\end{array}$ & 7 & 20 & 3 \\
Both sighted & 35 & 18 & 4 \\
\hline Totals & 43 & 41 & 10 \\
\hline McNemar's test $\chi^{2}$ & 5.14 & 15.43 & 0.33 \\
P & 0.025 & $<0.0005$ & $>0.25$ \\
\hline
\end{tabular}

vision. We have found that blindness will follow a vitreous haemorrhage as (1) a consequence of advancing cicatricial proliferative retinopathy; (2) failure of resorption of an extensive vitreous haemorrhage; (3) multiple vitreous haemorrhages; and (4) rarely a secondary glaucoma. We have shown that fewer treated eyes had vitreous haemorrhages, and that these arose much later in treated than in untreated eyes. This indicates that visual acuity may be retained for a significantly longer period after such events in treated eyes. The American study also suggested that vitreous haemorrhages in treated eyes resolved more rapidly than in untreated eyes. Better vision was retained in treated eyes from early optic disc neovascularisation to the onset of the late cicatricial stage. However, some cases with early epior peripapillary neovascularisation at the optic disc appeared to be in a quiescent phase. Treated eyes in the earlier stages of the proliferative process acted in the same way as these quiescent eyes and appeared 
to have been transformed into this stage while there was no progression. Treated eyes in the full-blown late cicatricial stage appeared to behave in the same way as untreated eyes. It is possible that careful treatment of the new vessels directly may improve prognosis for vision in this late group. Treatment of quiescent group 1 and also group 3 eyes was not shown to have significant deleterious effects on the eye. In view of this we would advise early treatment of all diabetics who are found to have neovascularisation at the optic disc.

Treatment in all cases should be adequate, and careful monitoring is necessary when this is accomplished. There are a significant number of patients who either achieve a less than desirable regression of new vessels or suffer a recurrence of the condition. These patients should receive timely repeat treatment.

Our thanks are due to Dr E. S. Rosen at the Manchester Royal Eye Hospital, and Dr Eva Kohner at the Royal Postgraduate Medical School, Hammersmith, for their interest and advice regarding this study; to Miss M. McDermott and Mr J. Sutton for help in the treatment of patients, and Miss Jayne Hughes for her work in the preparation of the paper. Our thanks are also due to Mr E. Young and Mr S. Shaw for their excellent photography.

\section{References}

Aiello, L. M., Beetham, W. P., Balodimos, M. C., and Koncz, L. (1969). Ruby laser photocoagulation in treatment of diabetic proliferating retinopathy preliminary report. In Goldberg, M. F., and Fine, S. L. (eds), Symposium on the treatment of diabetic retinopathy, Bulletin 1890, Public Health Service, pp. 437-463.

Beetham, W. P., Aiello, L. M., Balodimos, M. C., and Koncz, L. (1970). Ruby laser photocoagulation of early diabetic neovascular retinopathy. Archives of Ophthalmology, 83, 261-272.

British Multicentre Photocoagulation Trial (1977). Proliferative diabetic retinopathy: treatment with xenon-arc photocoagulation. British Medical Journal, 1, 739-741.
Caird, F. L., Burditt, A. F., and Draper, G. J. (1968). Diabetic Retinopathy: further study of prognosis for vision. Diabetes, 17, 121 .

Deckert, T., Simonsen, S. E., and Poulsen, J. E. (1967). Prognosis of proliferative retinopathy in juvenile diabetes. Diabetes, 6, 728.

Diabetic Retinopathy Study Research Group (1976). Preliminary report on the effects of photocoagulation therapy. American Journal of Ophthalmology, 81, 383-396.

James, W. A., and L'Esperance, F. A. (1974). Treatment of diabetic optic nerve neovascularization by extensive retinal photocoagulation. American Journal of Ophthamology, 78, 939-947.

Krill, A. E., Archer, D. B., and Newell, F. W. (1971a). Photocoagulation in complications secondary to branch vein occlusion. Archives of Ophthalmology, 85, 48.

Krill, A. E., Archer, D. B., Newell, F. W., and Chishti, M. I. (1971b). Photocoagulation in diabetic retinopathy. 72, 299-321.

Larsen, H. W. C. (1960). Diabetic retinopathy: with a discussion of the morphological changes and the pathogenic factors. Acta Ophthalmologica, Supplement 60, 42-46.

L'Esperance, F. A. (1968). An ophthalmic argon laser photocoagulation system: design, construction and laboratory investigations. Transactions of the American Ophthalmological Society, 66, 827-904.

L'Esperance, F. A. (1973). Argon laser photocoagulation of diabetic retinal neovascularization. A five-year appraisal. Transactions of the American Academy of Ophthalmology and Otolaryngology, 77, 6-24.

Little, H. L., Zweng, H. C., Jack, R. L., and Vassiliadis, A. (1976). Techniques of argon laser photocoagulation of diabetic disc new vessels. American Journal of Ophthalmology, 82, 675-683.

Meyer-Schwickerath, G. (1954). Lichtkoagulation. Eine methode zur Behandlung und Verhutung der Netzhautablosung. Albrecht von Graefes Archiv für Ophthalmologie, 156, 2-34.

Okun, E. (1968). The effectiveness of photocoagulation in the therapy of proliferative diabetic retinopathy (PDR). A controlled study in 50 patients. Transactions of the American Academy of Ophthalmology and Otolaryngology, 72, 246-252.

Patz, A., and Berkow, J. W. (1968). Visual and systemic prognosis in diabetic retinopathy. Transactions of the American Academy of Ophthalmology and Otolaryngology, 72, 253-258.

Sorsby, A. (1972). Incidence and Causes of Blindness in England and Wales, 1968, p. 10. HMSO: London.

Taylor, E., and Dobree, J. H. (1970). Proliferative diabetic retinopathy: site and size of initial lesions. British Journal of Ophthalmology, 54, 11-18. 